\title{
The Spectrum of MYC Alterations in Diffuse Large B-Cell Lymphoma
}

\author{
Yang Xia Xinlian Zhang \\ Department of Oncology, First People's Hospital of Lanzhou City, Lanzhou, PR China
}

\section{Keywords}

Diffuse large B-cell lymphoma - MYC · Double-hit lymphoma . Double-expressor-diffuse large B-cell lymphoma $\cdot$ MYC translocations

\begin{abstract}
MYC, as a powerful transcription factor, plays a vital role in various cancers. The clinical significance of MYC alterations in diffuse large B-cell lymphoma (DLBCL) has been investigated for a long time. In this study, we comprehensively summarize the different alterations of MYC in DLBCL, including MYC overexpression, MYC translocations, MYC mutations, and increased gene copy number of MYC. Noteworthy, lone MYC overexpression or MYC translocation is not significantly associated with poor clinical outcomes, and their detrimental effects depend on the genetic alterations of $B C L 2$ or BCL6. Both double-expressor DLBCL (DE-DLBCL), defined as overexpression of MYC and BCL2 proteins, and double-hit lymphoma (DHL), defined as a dual translocation of MYC together with $B C L 2$ or $B C L 6$, represent the distinct subgroups of DLBCL with inferior clinical outcomes. The mechanism may be that MYC activation induces cell proliferation, without the threat of the apoptotic brake in the presence of BCL2 overexpression. In addition, most of MYC mutations are present with favorable prognosis, and the nonsignificant effect
\end{abstract}

karger@karger.com

(c) 2020 S. Karger AG, Basel

www.karger.com/aha

Karger" of MYC copy number amplification has been observed. It has been proved that cyclophosphamide, doxorubicin, vincristine, and prednisone plus rituximab show limited effects for DHL or DE-DLBCL, and the rituximab plus dose-adjusted etoposide, prednisone, vincristine, cyclophosphamide, and doxorubicin seem to be efficacious for DHL. The novel therapy is urgently needed for clinical improvement in DHL and DE-DLBCL.

(c) 2020 S. Karger AG, Basel

\section{Introduction}

Non-Hodgkin lymphoma is one of the top 10 causes of cancer mortality and diffuse large B-cell lymphoma (DLBCL) comprises approximately $30-50 \%$ of NonHodgkin lymphoma $[1,2]$. DLBCL is a heterogeneous disease and can be identified as 2 molecular subtypes, termed germinal center B-cell-like (GCB) and activated B cell (ABC, or non-GC) [3]. Patients with the GCB subtype usually have better prognosis than those with the $A B C$ subtype [4]. Rituximab in combination with cyclophosphamide, doxorubicin, vincristine, and prednisone (R$\mathrm{CHOP}$ ) is the backbone of DLBCL treatment, but about $50 \%$ of DLBCL will relapse after R-CHOP treatment and $30 \%$ will succumb to this disease $[5,6]$. Various genetic 
and epigenetic alterations are associated with DLBCL genesis and development [3]. GCB DLBCL is preferentially involved in $M Y C$ translocation, $B C L 2$ translocation, and PTEN deletion, whereas ABC DLBCL is characterized by chronic active $B$ cell receptor (BCR) signaling and NF-kB deregulation [3, 7].

$M Y C$ gene, encoding the important transcription factor MYC, is located on the long arm of chromosome 8 (8q24) and under the transcription control of immunoglobulin (IG) gene [8]. MYC plays a pivotal role in tumor pathogenesis and development, with a wide range of biological activities, including apoptosis, growth, proliferation, differentiation, migration, and cellular metabolism [9-12]. MYC can bind the sequence-specific genes and drive their transcriptions to induce the oncogenic potentials of many cancers [13]. Aberrant activation of MYC can lead to the progress of various malignancies, including neuroblastoma, medulloblastoma, breast cancer, pancreatic ductal adenocarcinoma, and ovarian cancer [12, 14-19]. MYC alterations may be due to copy number gain, transcriptional/post-transcriptional events, epigenetic phenomena, or chromosomal translocations $[12,20]$. A plethora of articles have exploited MYC-related biological progresses and their effects on clinical outcomes in DLBCL, but no comprehensive knowledge of MYC alterations including MYC overexpression, MYC translocations, increased MYC copy number, and MYC mutations in DLBCL has been conducted $[12,21]$. This review will comprehensively conclude the potent effects of different MYC alterations and the treatment of DLBCL associated with MYC alterations.

\section{MYC Overexpression in DLBCL}

MYC protein can be detected in about $40 \%$ of whether newly diagnosed DLBCLs or relapsed patients [8]. Although many studies have reported that DLBCL patients with MYC overexpression were associated with inferior prognosis, the underlying mechanism is probably associated with the other genetic alterations in these patients, and the effect of lone MYC overexpression is probably not significant as we expected [20,22]. MYC overexpression can induce significant DNA damage and then lead to the apoptosis of cancer cell by increasing the expression of P53. Based on the MYC-driven lymphoma with transgenic mouse models, the tumors induced by $\mathrm{E} \mu$-myc transgene, with MYC overexpression, were generally clonal, and further study demonstrated that deregulated MYC promoted apoptosis by activating oncogenic stress response pathways. Therefore, the development of DLBCL requires additional oncogenic alteration to overcome the apoptosis [13]. It has been proved that the alterations of BCL2 and BCL6 can induce the oncogenic effect of MYC activation [20, 22].

A recent excellent review has summarized that the coexpression of MYC and BCL2 is a poor biomarker for prognosis in DLBCL [8]. BCL2, an antiapoptosis protein, can maintain cell viability by inhibiting apoptosis response. In normal lymphoid cells, genetic insults or oxidative stress inhibits BCL2 to promote apoptosis by increasing the expression of proteins of the $\mathrm{BH} 3$ family. In malignant lymphoma cells, overexpression of BCL2 caused by chromosomal translocations and increased gene copy number suppresses the apoptosis and promotes the malignant proliferation of lymphoma cells and finally accelerates the MYC-induced lymphomagenesis $[23,24]$. About $30 \%$ of DLBCL harbor both BCL2 and MYC overexpression, which is defined as double-expressor DLBCL (DE-DLBCL) [25]. Compared to DLBCL patients without double expression, DE-DLBCL patients are more likely to have old age at diagnosis, advanced stages, B symptoms, high international prognostic index (IPI), and inferior prognosis in $\mathrm{R}-\mathrm{CHOP}$ treated patients [3]. In addition, over $50 \%$ of relapsed/refractory DLBCL are DE-DLBCL [26]. In Savage et al. [27] study with a median follow-up of 6.8 years, DE-DCBCL treated by R$\mathrm{CHOP}$ had a higher risk of central nervous system (CNS) relapse compared to the nondual expressers (2-year risk, 9.7 vs. $2.2 \%$; $p=0.001$ ), independent of CNS-IPI score and cell of origin. According to Joel et al. [20] review, the 5 -year overall survival (OS) of DE-DLBCL was about 30$45 \%$, while the control was about $66-75 \%$. Recently, Green et al. [25] identified the double hit score, a sum of the immunoreactivity scores of MYC and BCL2, 1 (positive) or 0 (negative). Double hit score 2 represented both BCL2 and MYC overexpression (DE-DLBCL) and was associated with lower complete response rate $(p<0.004)$, shorter OS $(p<0.001)$, and shorter progression-free survival (PFS; $p<0.001$ ) [25]. Furthermore, some studies suggested that the prognostic value of DE-DLBCL was superior to cell of origin classification in the primary CNS DLBCLs [28, 29].

DE-DLBCL is more common in ABC-subtype disease (33-46\% ABC vs. $17 \% \mathrm{GCB}$ ); intriguingly, the prognostic significance of DE-DLBCL is more prominent in the GCB-subtype [20]. Furthermore, overexpression of MYC and BCL2 in DLBCL is mainly induced by activation of $B C R$ and NF- $\kappa B$ signaling in the $A B C$ patients, while are caused by the translocation of MYC and BCL2 in the GCB 
patients [30]. These findings indicate that targeting BCR and NF- $\kappa \mathrm{B}$ signaling maybe effective in ABC-DE-DLBCL [31]. The clinical outcomes of DE-DLBCL treated with RCHOP are intermediate between DLBCL without MYC/ BCL2 alterations and DLBCL with MYC and BCL2 cotranslocations [25].

Immunohistochemical (IHC) detection for DEDLBCL is simple and efficient and is necessary to take into routine. How to define the "positive expression" of IHC results has become a tough problem. According to different studies, the positive value of MYC and BCL2 ranges from 30 to 70 and 0 to $70 \%$, respectively. In addition, the technical biases, such as the sensitivity of antibody and the differences of manufactures, also result in the variability of IHC score. Nowadays, it is accepted that the positive values of MYC and BCL2 are 40 and 50\%, respectively, because of their close correlation with clinical outcomes, but the values are not the screening thresholds of FISH test for translocation [32].

\section{MYC Translocation in DLBCL}

MYC Translocation Requires the Second Hit to Serve as a "Vicious" Role

MYC translocation is reported in $7-21 \%$ of DLBCL $[33,34]$; and $M Y C$ translocation to an $I G$ locus, present in about $5 \%$ of DLBCL, induces the constitutively active transcription of MYC under the $I G$ promoter and causes the highest expressions of MYC mRNA and protein [8]. Copie-Bergman et al. [34] detected the MYC status in 774 DLBCL patients treated by R-CHOP using FISH testing and found that MYC-IG patients had shorter OS in comparison with MYC-negative patients, while no survival differences were observed between $M Y C$-non-IG and patients without $M Y C$ translocations. The dosage effect may explain that the MYC overexpression with a MYC-IG translocation has the worse clinical outcomes compared to other subtypes of translocations [33, 34]. Kluk et al. [35] study reported that DLBCL patients with MYC protein expression $\geq 50 \%$ were identified to have MYC translocations, whereas Green et al. [25] study showed that MYC protein expression $\geq 70 \%$ could be speculated to be with MYC translocations. Moreover, no MYC translocations were found in DLBCL patients without MYC expression [36].

The prognostic effect of the isolated MYC translocation without other gene translocations appears controversial $[8,34]$. A recent retrospective research analyzed 347 de novo DLBCL patients treated by R-CHOP and demonstrated that MYC translocations occurred in 19\% of GCB-DLBCL patients and 11\% ABC-DLBCL and was significantly associated with the worse time to progression whether in GCB-DLBCL or ABC-DLBCL [21]. Cuccuini et al. [37] study found that $M Y C$ translocation was present in $17 \%$ of relapsed/refractory DLBCL prospectively treated by R-ICE or R-DHAP and compared to DLBCL patients without MYC translocations, DLBCL patients with $M Y C$ translocations showed as a higher lactico-deshydrogenase level $(p=0.0006)$ and shorter 4 -year PFS (18 vs. $42 \%, p=0.0322$ ) and OS (29 vs. $62 \%, p=$ 0.0113 ) which was consistent with another study. However, it was recently reported that $74 \%$ of $M Y C$-translocated DLBCL harbored a "second hit" defined as either $B C L 2$ and BCL6 translocations or TP53 mutations, and the clinical effects of $M Y C$ rearrangement may be induced by the underlying double hit [20]. A large clinical cohort conducted by Johnson et al. [32] found that 5-year OS was $>90 \%$ in DLBCL patients with MYC translocations but without BCL2 expression $[8,32]$. In addition, Alexandra et al. [38] study also pointed out that the prognosis of MYC translocations in DLBCL depended on the second hit and if without the BCL2 and BCL6 translocations or TP53 mutations, the clinical outcomes of MYCtranslocated DLBCL patients were excellent, with $90 \%$ remaining in remission beyond 8 years. So, the "vicious" effect of MYC translocations is significantly dependent on the second hit. Both BCL2 and BCL6 overexpression can lead to dysregulation of the apoptotic response [39]; therefore, the possible mechanism is that the other genetic aberrations are able to overcome the proapoptotic effects induced by MYC aberrations. Based on these findings, DLBCL with positive MYC expression should be conducted for the FISH to detect MYC, BCL2, and BCL6 translocations; and including analysis for TP53 mutations is much better.

\section{Double-Hit Lymphoma Is Significantly Associated with Poor Prognosis}

Double-hit lymphoma (DHL) is defined as the highgrade B-cell lymphomas with MYC translocations and either BCL2 or BCL6 translocations by the newest version of world health organization classification, a separate subtype with an aggressive entity [7]. According to the 2016 revision of the world health organization classification, this subtype is morphologically heterogeneous and can have morphological features of blastoid, Burkitt lymphoma, DLBCL, and intermediate between DLBCL and Burkitt lymphoma [13]. And more, about $65 \%$ of DHL patients harbored translocations of $M Y C$ 
and $B C L 2 ; 14 \%$ were with translocations of $M Y C$ and $B C L 6$, and the remaining $21 \%$ had all 3 translocations, called as triple-hit lymphoma (THL) [40]. In clinical setting, it is demonstrated that DHL patients have the advanced lactate dehydrogenase level, IPI score, disease stage, and poor clinical outcomes $[8,24]$. In addition, DHLs were associated with CNS involvement with 4-7\% of patients at the risk of CNS relapse/progression $[3,24]$. Although a big overlap exists between DHL and DEDLBCL, they have the differences in some regards. Over $90 \%$ of DHLs were in GCB-DLBCL, whereas over $60 \%$ of DE-DLBCLs occurred in ABC-DLBCL [41]. Noteworthy, almost $20 \%$ of DHL patients were not with MYC and BCL2 overexpression, and this part of patients were associated with better clinical prognosis compared to DE-DLBCL patients [42].

Furthermore, concurrent $M Y C$ and BCL2 translocations seem different to $M Y C$ and BCL6 translocations. The studies conducted by Ye et al. [43] and Copie-Bergman et al. [34] demonstrated that MYC and BCL2 cotranslocations were associated with inferior outcomes compared to MYC and BCL6 cotranslocations in DLBCL treated by R-CHOP. In contrast, Landsburg et al. [40] reported that patients with MYC and BCL6 cotranslocations were significantly associated with worse median OS (14.5 months) than MYC and BCL2 cotranslocations or THL (34.8 and 17.2 months, respectively). Therefore, more studies are needed to evaluate whether the clinical effects of 2 subtypes of DHL are equivalent in DLBCL. The clinicopathological characteristics and outcomes of THL were similar to the DHL patients [36]. As stated above, simultaneous $M Y C$ and $B C L 2$ translocations are more common than MYC and BCL6 DHL and THL; and hence, the double hit of $M Y C$ and BCL2 translocations in DLBCL will be the focus of attention.

\section{No Detection Standard for MYC Translocations has been Established}

The gold standard for detecting DHL is FISH, but FISH costs much and is difficult to be operated. Nowadays, there is no standard guidance on which DLBCL patients require FISH testing. A recent study reported when MYC expression level was $\geq 30 \%$ by IHC, the FISH testing was needed [44]; however, other studies reported some patients with $M Y C$-rearranged DLBCL could have the protein level below the threshold [45]. And according to Wang et al. [46] study, when FISH testing was only conducted in DLBCL patients with $>40 \%$ of MYC expression, about $20 \%$ of the $M Y C$-rearranged patients might be missed. Therefore, it is necessary to perform FISH testing in every newly diagnosed DLBCL and if patients are confirmed with $M Y C$ translocations, it is recommended to conduct FISH testing for BCL2 and BCL6 [21].

\section{MYC Mutations in DLBCL}

MYC mutations in DLBCL were not as well investigated as MYC translocations. Xu-Monette et al. [47] study identified MYC mutations in 750 DLBCL patients using Sanger sequencing and demonstrated that $33.3 \%$ of patients harbored MYC mutations at the DNA level and $16.1 \%$ at the protein level (nonsynonymous mutations). The further results showed that MYC T58 and F138 mutations, which were only in $2 \%$ of DLBCL, were associated with $M Y C$ translocations and significantly associated with poor clinical outcomes. Most of the nonsynonymous mutations were associated with better prognosis compared to MYC translocations [4, 47]. It may be because the nonsynonymous mutations of $M Y C$ hamper the oncogenic functions of MYC in DLBCL. In addition, Ennishi et al. [21] research observed that the hotspot mutations of MYC, defined as $>2$ single nucleotide variants, had no significant association with clinical outcomes of GCB-DLBCL, while no hotspot mutations were identified in ABC-DLBCL. In other words, most MYC mutations are passenger mutations instead of driver mutations during genesis and development of DLBCL [4].

\section{Increased Gene Copy Number of MYC in DLBCL}

Increased MYC gene copy number exists in $8-20 \%$ of DLBCL patients and is not definitely associated with increased MYC protein expression [5, 8, 48]. MYC copy number amplification is more common in GCB-DLBCL than ABC-DLBCL [21]. The studies of MYC copy amplification in DLBCL are limited, and the existing data draw the conflicting results about the prognosis of increased copy number of MYC in DLBCL.

Landsburg et al. [49] study including 22 DLBCL patients with $M Y C$-amplification, 87 patients with singlehit, and 127 patients without MYC amplification or translocation, reported that $M Y C$-amplified DLBCL had similar 2-year OS to the MYC-negative ones. Bryn et al. [5] study also reported that no distinct differences were observed between DLBCL with increased MYC gene copy number (33 cases) and DLBCL with no MYC aberrations (43 cases). However, some studies reported that MYC extra copy was associated with inferior prognosis $[21,50]$. 
Quesada et al. [50] retrospective study demonstrated that within 80 DLBCL patients with MYC overexpression, $M Y C$ amplification was associated with inferior OS and more interestingly, patients with double or triple extra copy lymphoma (defined by MYC and BCL2 and/or BCL6 amplification) have similar prognosis to these DHL or THL. In addition, Valera et al. [51] study pointed out that the role of MYC extra copy in DLBCL was affected by the copy number of $M Y C$ gene. The nonsignificant effect of MYC copy number amplification can be explained by the no evident relationship between high MYC expression and increased copy number [21].

\section{Treatment for DHL and DE-DLBCL}

\section{Intensified Chemotherapy May Be Only Choice}

A retrospective study demonstrated that DHL patients treated with RCHOP had significantly inferior outcome compared to DLBCL without MYC/BCL2 alterations (5year PFS: 18 vs. $65 \%$; 5-year OS: 27 vs. $71 \%$ ), and those with DE-DLBCL also showed worse outcomes (5-year PFS: 32\% and 5-year OS: 36\%) [32]. Combined with other larger retrospective studies, the R-CHOP in DLBCL is suboptimal for DHL and DE-DLBCL [52-54].

Petrich et al. [52] conducted a large retrospective study to explore R-CHOP and other intensive induction regimens among 311 DHL patients, and the results demonstrated that patients treated by intensive induction regimens had better median PFS in comparison with RCHOP therapy (7.8 vs. 21.6 months; $p=0.001)$, but no OS benefit. The initial results of a prospective clinical trial of rituximab plus dose-adjusted etoposide, prednisone, vincristine, cyclophosphamide, and doxorubicin (DA-R-EPOCH) on MYC translocated DLBCL $(n=52)$, which included 14 DHL patients and 24 patients with overexpressed BCL2, showed that within a median follow-up of 14 months, the PFS was $87 \%$ for DHL, suggesting that compared to RCHOP, DA-R-EPOCH could induce higher clinical response rate [53]. A meta-analysis of 11 studies involving 394 DHL patients indicated that DA-R-EPOCH reduced the risk of progression compared to R-CHOP, but no OS difference was observed [54]. In spite of no OS benefit, the institutional experience of MD Anderson Cancer Center still highlighted the importance of DA-R-EPOCH in the treatment of DHL [55]. However, not all intensified chemotherapy therapies for DHL are favorable [56]. The intensification of therapy, rituximab, high-dose methotrexate, and cytarabine regimen (R-hyper-CVAD) has been reported to not affect the clinical outcomes $[57,58]$. Therefore, by far, DA-R-EPOCH seems the most favorable chemotherapy with a higher complete response rate than R-CHOP and the less adverse effects compared to the other high-dose chemotherapies [52]. Although intensive induction regimens show prospects in treatment of DHL, most of these DHL patients are elderly and/or frail, which make them unavailable to the high-dose chemotherapy [56]. Thus, the more effective therapies are urgently needed for DHL.

No grand-scale studies were analyzed specifically for treatment of DE-DLBCL. A small retrospective clinical trial encompassing $16 \mathrm{DE}-\mathrm{DLBCL}$ patients showed that the relapse rate in $\mathrm{R}-\mathrm{CHOP}$ groups was significantly higher than it in DA-R-EPOCH group (80 vs. $18 \%, p=$ 0.042) [59]. However, subgroup analysis from Cancer and Leukemia Group B 50303 trial and the GOYA trial demonstrated that no extra benefits were observed in $\mathrm{DE}$ DLBCL patients treated with intensive chemotherapy in comparison with R-CHOP [24]. As a result of the limited data, the decision to determine which one of R-CHOP and intensive chemotherapy cannot be made for DEDLBCL.

Because of the increased possibility of CNS invasion in DHL and DE-DLBCL patients, the CNS prophylaxis is strongly considered. Whereby, DA-R-EPOCH with CNS prophylaxis was empirically recommended [56]. However, the ultimate decision still needs the prospective clinical trials in DHL and DE-DLBCL patients.

As for consolidative hematopoietic stem cell transplant (SCT) for DHL/DE-DLBCL patients, the available data are also limited, and the results are not optimistic [56]. Some retrospective studies demonstrated that autologous SCT (ASCT) during first complete remission after chemotherapy failed to get an improvement of PFS and OS in DHL $[52,60]$. Recently, a large clinical trial about ASCT in DHL patients who achieved first complete remission following completion of R-CHOP or intensive therapy demonstrated that 3-year relapse-free survival and OS rates showed no significant difference between ASCT $(n=62)$ and non-ASCT patients $(n=97 ; 3$-year relapse-free survival rate: 75 vs. $89 \%, p=0.12$; 3 -year OS rate: 85 vs. $91 \%, p=0.74$ ) [61]. However, the study by Maura et al. [62] suggested that transplant consolidation followed with high-dose chemotherapy could contend against the poor prognostic effect of DE-DLBCL among young and/or fit DLBCL patients regardless of whether in first line or first relapse.

Conclusively, although intensive induction regimens for DHL or DE-DLBCL are accepted by most centers, 
Table 1. Clinical features and treatments of DLBCL with MYC alterations

\begin{tabular}{|c|c|c|}
\hline MYC alterations in DLBCL & Clinical associations & Special treatments \\
\hline \multicolumn{3}{|l|}{ MYC translocations (7-21\%) } \\
\hline Sole MYC rearrangement & Clinical prognosis is dependent on the second hit & - \\
\hline DHL (5-6\%) & $\begin{array}{l}\text { GCB-subtype, high IPI score, advanced stages, } \\
\text { CNS involvement, and poor prognosis }\end{array}$ & $\begin{array}{l}\text { DA-R-EPOCH with CNS prophylaxis } \\
\text { is empirically recommended. Clinical } \\
\text { trials is especially encouraged }\end{array}$ \\
\hline DE-DLBCL (30\%) & $\begin{array}{l}\text { ABC subtype, high IPI score, advanced stages, } \\
\text { higher risk of CNS relapse, and poor prognosis }\end{array}$ & Refer to the treatments of DHL \\
\hline MYC mutation (33.3\%) & Most MYC mutations are passenger mutations & - \\
\hline Increased MYC copy number (8-20\%) & Nonsignificant clinical effect & - \\
\hline
\end{tabular}

firm conclusions from prospective clinical trials designed for DHL are urgently needed. Besides, the new targeted drugs for DHL or DE-DLBCL targeting oncogenic alterations are urgently needed.

\section{Drugs Targeting MYC}

Although targeting MYC directly has been explored for several decades, thus far no effective drugs have been produced [63]. As MYC protein seems "undruggable," diverse compounds have been developed to inhibit activities of MYC in various ways, including destroying the interaction between MYC and MAX and suppressing the MYC-dependent transcription [64]. Targeting MYC-regulated transcription has been studied for a long time. HDACs are recruited to the promoter regions of MYCmediated genes to promote the transcription of MYCtargeted genes. Thus, HDAC inhibitors will lead to the decreased expression of MYC-targeted genes, including MYC itself $[63,65]$. Inhibition of PI3K pathway has also been demonstrated to deregulate MYC activities by suppressing MYC gene transcription $[63,66]$. Although single-agent HDAC or PI3K inhibitor has not shown effective antitumor activity in DLBCL, synergistic lethality of HDAC and PI3K inhibitors has been observed in DLBCL xenograft tumors [67]. A recent phase I clinical trial demonstrated that the dual HDAC and PI3K inhibitor, CUDC-907, showed encouraging and durable antitumor activity in MYC-altered DLBCL patients [42,68]. And the phase II clinical trial of CUDC-907 is ongoing [26]. Be- sides, bromodomain and extra-terminal motif inhibitors can prevent the transcription regulated by MYC and then inhibit the cancer cell proliferation [26]. The bromodomain and extra-terminal motif bromodomain inhibitor, JQ1, has demonstrated anti-tumor effects by repressing MYC and its target genes in MYC-driven lymphomas in vitro and vivo, including $M Y C$-rearranged DLBCL [69]. Based on the speculation that targeting the curial effectors in deregulated MYC activity may induce the synthetic lethality, inhibitors of kinases in cell cycle progress, including CDKs inhibitors, CHK1 inhibitors, and aurora kinase inhibitors, also show prospects in treatment of $M Y C$-rearranged DLBCL [13]. In conclusion, clinical trials evaluating novel regimens will be the preferred choice for DEDLBCL and DHL.

\section{Conclusion}

Here, we conclude the clinical characteristics and treatments of DLBCL with MYC alterations, including MYC overexpression, MYC translocations, MYC copy number amplification, and MYC mutations (Table 1). The prognostic effect of lone MYC translocation or MYC overexpression is still in controversy, and the dominant view is that lone MYC translocation or MYC overexpression does not induce the poorer clinical outcomes compared to the MYC-negative DLBCL patients. DEDLBCL and DHL have been proved to be significantly 
associated with poor clinical prognosis. Most of $M Y C$ mutations are present with favorable prognosis, and the nonsignificant effect of $M Y C$ copy number amplification has been observed; and nevertheless, the effects of MYC mutations and increased MYC copy number may depend on the mutation subtypes and the copy number, respectively. Based on the existent data, the available treatment for DHL and DE-DLBCL is the intensified chemotherapy, especially DA-R-EPOCH. And it is urgently needed to develop the novel-targeted drugs for DHL and DE-DLBCL.

\section{Statement of Ethics}

Not applicable.

\section{Disclosure Statement}

The authors declare that they have no competing interests.

\section{Funding Sources}

There are no funding sources to declare.

\section{Acknowledgments}

Not applicable.

\section{Author Contributions}

Y.X. consulted literature and wrote the paper. X.Z. gave advices.

\section{References}

1 Zou D, Yi S, Cui R, Liu W, Li C, Zhong S, et al. BCL-2 and MYC gain/amplification is correlated with central nervous system involvement in diffuse large B cell lymphoma at leukemic phase. BMC Med Genet. 2017 Feb; 18(1):16.

2 Norris D, Stone J. WHO classification of tumours of haematopoietic and lymphoid tissues. Geneva: WHO; 2008.

3 Nowakowski GS, Blum KA, Kahl BS, Friedberg JW, Baizer L, Little RF, et al. Beyond RCHOP: a blueprint for diffuse large B cell lymphoma research. J Natl Cancer Inst. 2016 Dec;108(12):djw257.

4 Xu-Monette ZY, Deng Q, Manyam GC, Tzankov A, Li L, Xia Y, et al. Clinical and Biologic Significance of MYC Genetic Mutations in De Novo Diffuse Large B-cell Lymphoma. Clin Cancer Res. 2016 Jul;22(14):3593-605.

5 Haws BT, Cui W, Persons DL, Zhang D. Clinical and pathologic correlation of increased MYC gene copy number in diffuse large B-cell lymphoma. Clin Lymphoma Myeloma Leuk. 2016 Dec;16(12):679-83.

6 Cunningham D, Hawkes EA, Jack A, Qian W, Smith P, Mouncey P, et al. Rituximab plus cyclophosphamide, doxorubicin, vincristine, and prednisolone in patients with newly diagnosed diffuse large B-cell non-Hodgkin lymphoma: a phase 3 comparison of dose intensification with 14-day versus 21 -day cycles. Lancet. 2013 May;381(9880):1817-26.

7 Swerdlow SH, Campo E, Pileri SA, Harris NL, Stein H, Siebert R, et al. The 2016 revision of the World Health Organization classification of lymphoid neoplasms. Blood. 2016 May; 127(20):2375-90.

8 Sesques P, Johnson NA. Approach to the diagnosis and treatment of high-grade B-cell lymphomas with MYC and BCL2 and/or BCL6 rearrangements. Blood. 2017 Jan;129(3):280-8.
9 Meyer N, Penn LZ. Reflecting on 25 years with MYC. Nat Rev Cancer. 2008 Dec;8(12): 976-90.

10 Dang CV. MYC on the path to cancer. Cell. 2012 Mar; 149(1):22-35.

11 Ott G, Rosenwald A, Campo E. Understanding MYC-driven aggressive B-cell lymphomas: pathogenesis and classification. Blood. 2013 Dec;122(24):3884-91.

12 Jung M, Russell AJ, Liu B, George J, Liu PY, Liu T, et al. A Myc activity signature predicts poor clinical outcomes in Myc-associated cancers. Cancer Res. 2017 Feb;77(4):971-81.

13 Bisso A, Sabò A, Amati B. MYC in Germinal Center-derived lymphomas: mechanisms and therapeutic opportunities. Immunol Rev. 2019 Mar;288(1):178-97.

14 Brodeur GM. Neuroblastoma: biological insights into a clinical enigma. Nat Rev Cancer. 2003 Mar;3(3):203-16.

15 Roussel MF, Robinson GW. Role of MYC in Medulloblastoma. Cold Spring Harb Perspect Med. 2013 Nov;3(11):a014308.

16 Valera A, López-Guillermo A, Cardesa-Salzmann T, Climent F, González-Barca E, Mercadal S, et al.; Grup per l'Estudi dels Limfomes de Catalunya i Balears (GELCAB). MYC protein expression and genetic alterations have prognostic impact in patients with diffuse large B-cell lymphoma treated with immunochemotherapy. Haematologica. 2013 Oct; 98(10):1554-62.

17 Skoudy A, Hernández-Muñoz I, Navarro P. Pancreatic ductal adenocarcinoma and transcription factors: role of c-Myc. J Gastrointest Cancer. 2011 Jun;42(2):76-84.

18 Deming SL, Nass SJ, Dickson RB, Trock BJ. C-myc amplification in breast cancer: a metaanalysis of its occurrence and prognostic relevance. Br J Cancer. 2000 Dec;83(12):168895.
19 Darcy KM, Brady WE, Blancato JK, Dickson RB, Hoskins WJ, McGuire WP, et al. Prognostic relevance of c-MYC gene amplification and polysomy for chromosome 8 in suboptimally-resected, advanced stage epithelial ovarian cancers: a Gynecologic Oncology Group study. Gynecol Oncol. 2009 Sep; 114(3):472-9.

20 Wight JC, Chong G, Grigg AP, Hawkes EA. Prognostication of diffuse large B-cell lymphoma in the molecular era: moving beyond the IPI. Blood Rev. 2018 Sep;32(5):400-15.

21 Ennishi D, Mottok A, Ben-Neriah S, Shulha HP, Farinha P, Chan FC, et al. Genetic profiling of MYC and BCL2 in diffuse large B-cell lymphoma determines cell-of-origin-specific clinical impact. Blood. 2017 May;129(20): 2760-70.

22 Miyamoto K, Kobayashi Y, Maeshima AM, Taniguchi H, Nomoto J, Kitahara H, et al. Clinicopathological prognostic factors of 24 patients with B-cell lymphoma, unclassifiable, with features intermediate between diffuse large B-cell lymphoma and Burkitt lymphoma. Int J Hematol. 2016 Jun;103(6):693702 .

23 Ting CY, Chang KM, Kuan JW, Sathar J, Chew LP, Wong OJ, et al. Clinical Significance of BCL2, C-MYC, and BCL6 Genetic Abnormalities, Epstein-Barr Virus Infection, CD5 Protein Expression, Germinal Center B Cell/Non-Germinal Center B-Cell Subtypes, Co-expression of MYC/BCL2 Proteins and Co-expression of MYC/BCL2/BCL6 Proteins in Diffuse Large B-Cell Lymphoma: A Clinical and Pathological Correlation Study of 120 Patients. Int J Med Sci. 2019 Apr;16(4):55666.

24 Riedell PA, Smith SM. Double hit and double expressors in lymphoma: definition and treatment. Cancer. 2018 Dec;124(24):4622-32. 
25 Green TM, Young KH, Visco C, Xu-Monette ZY, Orazi A, Go RS, et al. Immunohistochemical double-hit score is a strong predictor of outcome in patients with diffuse large B-cell lymphoma treated with rituximab plus cyclophosphamide, doxorubicin, vincristine, and prednisone. J Clin Oncol. 2012 Oct;30(28): 3460-7.

26 Liu Y, Barta SK. Diffuse large B-cell lymphoma: 2019 update on diagnosis, risk stratification, and treatment. Am J Hematol. 2019 May;94(5):604-16.

27 Savage KJ, Slack GW, Mottok A, Sehn LH, Villa D, Kansara R, et al. Impact of dual expression of MYC and BCL2 by immunohistochemistry on the risk of CNS relapse in DLBCL. Blood. 2016 May;127(18):2182-8.

28 Kim S, Nam SJ, Kwon D, Kim H, Lee E, Kim TM, et al. MYC and BCL2 overexpression is associated with a higher class of Memorial Sloan-Kettering Cancer Center prognostic model and poor clinical outcome in primary diffuse large B-cell lymphoma of the central nervous system. BMC Cancer. 2016 Jun; 16(1):363.

29 Shi QY, Feng X, Bao W, Ma J, Lv JH, Wang X, et al. MYC/BCL2 co-expression is a stronger prognostic factor compared with the cell-oforigin classification in primary CNS DLBCL. J Neuropathol Exp Neurol. 2017 Nov;76(11): $942-8$.

30 Wierstra I, Alves J. The c-myc promoter: still MysterY and challenge. Adv Cancer Res. 2008;99:113-333.

31 Wang WG, Liu ZB, Jiang XN, Lee J, Zhou XY, Li XQ. MYC protein dysregulation is driven by BCR-PI3K signalling in diffuse large B-cell lymphoma. Histopathology. 2017 Nov;71(5): 778-85.

32 Johnson NA, Slack GW, Savage KJ, Connors JM, Ben-Neriah S, Rogic S, et al. Concurrent expression of MYC and BCL2 in diffuse large B-cell lymphoma treated with rituximab plus cyclophosphamide, doxorubicin, vincristine, and prednisone. J Clin Oncol. 2012 Oct; 30(28):3452-9.

33 Barrans S, Crouch S, Smith A, Turner K, Owen R, Patmore R, et al. Rearrangement of MYC is associated with poor prognosis in patients with diffuse large B-cell lymphoma treated in the era of rituximab. J Clin Oncol. 2010 Jul;28(20):3360-5.

34 Copie-Bergman C, Cuillière-Dartigues $\mathrm{P}$, Baia M, Briere J, Delarue R, Canioni D, et al. MYC-IG rearrangements are negative predictors of survival in DLBCL patients treated with immunochemotherapy: a GELA/LYSA study. Blood. 2015 Nov;126(22):2466-74.

35 Kluk MJ, Chapuy B, Sinha P, Roy A, Dal Cin $P$, Neuberg DS, et al. Immunohistochemical detection of MYC-driven diffuse large B-cell lymphomas. PLoS One. 2012;7(4):e33813.

36 Zhang Y, Wang H, Ren C, Yu H, Fang W, Zhang N, et al. Correlation Between C-MYC, BCL-2, and BCL-6 Protein Expression and Gene Translocation as Biomarkers in Diagnosis and Prognosis of Diffuse Large B-cell
Lymphoma. Front Pharmacol. 2019 Jan;9: 1497.

37 Cuccuini W, Briere J, Mounier N, Voelker HU, Rosenwald A, Sundstrom C, et al. MYC+ diffuse large B-cell lymphoma is not salvaged by classical R-ICE or R-DHAP followed by BEAM plus autologous stem cell transplantation. Blood. 2012 May;119(20):4619-24.

38 Clipson A, Barrans S, Zeng N, Crouch S, Grigoropoulos NF, Liu H, et al. The prognosis of MYC translocation positive diffuse large Bcell lymphoma depends on the second hit. J Pathol Clin Res. 2015 Mar;1(3):125-33.

39 Davies A. Double-hit lymphoma: so what? Hematol Oncol. 2019 Jun;37(S1 Suppl 1):1923.

40 Landsburg DJ, Petrich AM, Abramson JS, Sohani AR, Press O, Cassaday R, et al. Impact of oncogene rearrangement patterns on outcomes in patients with double-hit non-Hodgkin lymphoma. Cancer. 2016 Feb;122(4):55964.

41 Mottok A, Gascoyne RD. Bromodomain inhibition in diffuse large B-cell lymphoma-giving MYC a brake. Clin Cancer Res. 2015 Jan; 21(1):4-6.

42 Herrera AF, Mei M, Low L, Kim HT, Griffin GK, Song JY, et al. Relapsed or refractory double-expressor and double-hit lymphomas have inferior progression-free survival after autologous stem-cell transplantation. J Clin Oncol. 2017 Jan;35(1):24-31.

43 Ye Q, Xu-Monette ZY, Tzankov A, Deng L, Wang X, Manyam GC, et al. Prognostic impact of concurrent MYC and BCL6 rearrangements and expression in de novo diffuse large B-cell lymphoma. Oncotarget. 2016 Jan;7(3): 2401-16.

44 Agarwal R, Lade S, Liew D, Rogers TM, Byrne D, Feleppa F, et al. Role of immunohistochemistry in the era of genetic testing in MYC-positive aggressive B-cell lymphomas: a study of 209 cases. J Clin Pathol. 2016 Mar; 69(3):266-70.

45 Friedberg JW. How I treat double-hit lymphoma. Blood. 2017 Aug;130(5):590-6.

46 Wang XJ, Medeiros LJ, Lin P, Yin CC, Hu S, Thompson MA, et al. MYC cytogenetic status correlates with expression and has prognostic significance in patients with MYC/BCL2 protein double-positive diffuse large B-cell lymphoma. Am J Surg Pathol. 2015 Sep;39(9): $1250-8$.

47 Xu-Monette ZY, Deng Q, Manyam GC, Tzankov A, Li L, Xia Y, et al. Clinical and biologic significance of MYC genetic mutations in de novo diffuse large B-cell lymphoma. Clin Cancer Res. 2016 Jul;22(14):3593-605.

48 Lu TX, Fan L, Wang L, Wu JZ, Miao KR, Liang JH, et al. MYC or BCL2 copy number aberration is a strong predictor of outcome in patients with diffuse large B-cell lymphoma. Oncotarget. 2015 Jul;6(21):18374-88.

49 Landsburg DJ, Falkiewicz MK, Petrich AM, Chu BA, Behdad A, Li S, et al. Sole rearrangement but not amplification of MYC is associated with a poor prognosis in patients with diffuse large B cell lymphoma and B cell lymphoma unclassifiable. Br J Haematol. 2016 Nov; 175(4):631-40.

50 Quesada AE, Medeiros LJ, Desai PA, Lin P, Westin JR, Hawsawi HM, et al. Increased MYC copy number is an independent prognostic factor in patients with diffuse large Bcell lymphoma. Mod Pathol. 2017 Dec;30(12): 1688-97.

51 Valera A, López-Guillermo A, Cardesa-Salzmann T, Climent F, González-Barca E, Mercadal S, et al.; Grup per l'Estudi dels Limfomes de Catalunya i Balears (GELCAB). MYC protein expression and genetic alterations have prognostic impact in patients with diffuse large B-cell lymphoma treated with immunochemotherapy. Haematologica. 2013 Oct; 98(10):1554-62.

52 Petrich AM, Gandhi M, Jovanovic B, Castillo JJ, Rajguru S, Yang DT, et al. Impact of induction regimen and stem cell transplantation on outcomes in double-hit lymphoma: a multicenter retrospective analysis. Blood. 2014 Oct; 124(15):2354-61.

53 Dunleavy K, Fanale M, LaCasce A, Noy A, Caimi P, Parekh S, et al. Preliminary Report of a Multicenter Prospective Phase II Study of DA-EPOCH-R in MYC-Rearranged Aggressive B-Cell Lymphoma. Blood. 2014;124(21): 395.

54 Howlett C, Snedecor SJ, Landsburg DJ, Svoboda J, Chong EA, Schuster SJ, et al. Frontline, dose-escalated immunochemotherapy is associated with a significant progression-free survival advantage in patients with double-hit lymphomas: a systematic review and metaanalysis. Br J Haematol. 2015 Aug; 170(4): 504-14.

55 Oki Y, Noorani M, Lin P, Davis RE, Neelapu SS, Ma L, et al. Double hit lymphoma: the MD Anderson Cancer Center clinical experience. Br J Haematol. 2014 Sep;166(6):891901.

56 Rosenthal A, Younes A. High grade B-cell lymphoma with rearrangements of MYC and BCL2 and/or BCL6: double hit and triple hit lymphomas and double expressing lymphoma. Blood Rev. 2017 Mar;31(2):37-42.

57 Li S, Lin P, Fayad LE, Lennon PA, Miranda $\mathrm{RN}$, Yin CC, et al. B-cell lymphomas with MYC/8q24 rearrangements and IGH@ $\mathrm{BCL} 2 / \mathrm{t}(14 ; 18)(\mathrm{q} 32 ; \mathrm{q} 21)$ : an aggressive disease with heterogeneous histology, germinal center B-cell immunophenotype and poor outcome. Mod Pathol. 2012 Jan;25(1):14556.

58 Pedersen MØ, Gang AO, Poulsen TS, Knudsen $\mathrm{H}$, Lauritzen AF, Nielsen SL, et al. Double-hit BCL2/MYC translocations in a consecutive cohort of patients with large B-cell lymphoma - a single centre's experience. Eur J Haematol. 2012 Jul;89(1):63-71.

59 Aggarwal A, Rafei H, Alakeel F, Finianos AN, Liu ML, El-Bahesh E, et al. Outcome of patients with double-expressor lymphomas (DELs) treated with R-CHOP or R-EPOCH. Blood 2016 Dec;128(22):5396. 
60 Chen AI, Leonard JT, Okada CY, Gay ND, Chansky K, Fan G, et al. Outcomes of DA$\mathrm{EPOCH}-\mathrm{R}$ induction plus autologous transplant consolidation for double hit lymphoma. Leuk Lymphoma. 2018 Aug;59(8):1884-9.

61 Landsburg DJ, Falkiewicz MK, Maly J, Blum KA, Howlett C, Feldman T, et al. Outcomes of Patients With Double-Hit Lymphoma Who Achieve First Complete Remission. J Clin Oncol. 2017 Jul;35(20):2260-7.

62 Maura F, Guidetti A, Pellegrinelli A, Dodero A, Pennisi M, Caprioli C, et al. High-dose chemotherapy followed by autologous transplantation may overcome the poor prognosis of diffuse large B-cell lymphoma patients with MYC/BCL2 co-expression. Blood Cancer J. 2016 Nov;6(11):e491.
63 Sun K, Atoyan R, Borek MA, Dellarocca S, Samson ME, Ma AW, et al. Dual HDAC and PI3K inhibitor CUDC-907 downregulates MYC and suppresses growth of MYC-dependent cancers. Mol Cancer Ther. 2017 Feb; 16(2):285-99.

64 Derenzini E, Mondello P, Erazo T, Portelinha A, Liu Y, Scallion M, et al. BET InhibitionInduced GSK3 $\beta$ Feedback Enhances Lymphoma Vulnerability to PI3K Inhibitors. Cell Rep. 2018 Aug;24(8):2155-66.

65 Bhadury J, Nilsson LM, Muralidharan SV, Green LC, Li Z, Gesner EM, et al. BET and HDAC inhibitors induce similar genes and biological effects and synergize to kill in Mycinduced murine lymphoma. Proc Natl Acad Sci USA. 2014 Jul;111(26):E2721-30.

66 Dey N, Leyland-Jones B, De P. MYC-xing it up with PIK3CA mutation and resistance to PI3K inhibitors: summit of two giants in breast cancers. Am J Cancer Res. 2014 Dec; 5(1):1-19.
67 Gupta M, Ansell SM, Novak AJ, Kumar S, Kaufmann SH, Witzig TE. Inhibition of histone deacetylase overcomes rapamycin-mediated resistance in diffuse large B-cell lymphoma by inhibiting Akt signaling through mTORC2. Blood. 2009 Oct;114(14):2926-35.

68 Oki Y, Kelly KR, Flinn I, Patel MR, Gharavi R, Ma A, et al. CUDC-907 in relapsed/refractory diffuse large B-cell lymphoma, including patients with MYC-alterations: results from an expanded phase I trial. Haematologica. 2017 Nov;102(11):1923-30.

69 Trabucco SE, Gerstein RM, Evens AM, Bradner JE, Shultz LD, Greiner DL, et al. Inhibition of bromodomain proteins for the treatment of human diffuse large B-cell lymphoma. Clin Cancer Res. 2015 Jan;21(1):113-22. 